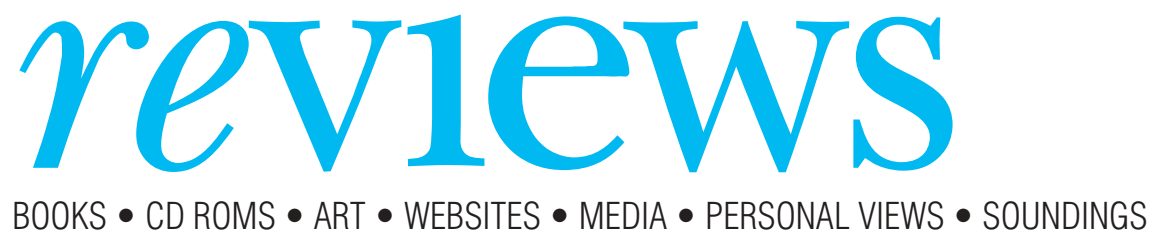

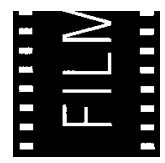

\section{An Inconvenient Truth}

US release date: 24 May

UK release date: 8 September www.climatecrisis.net/

\section{Rating: $\star \star \star \star$}

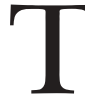

The truth can be a bitter pill to swallow and An Inconvenient Truth contains the active ingredients: evidence of disruption of the Earth's atmosphere, biosphere, bathysphere, and cryosphere (ice cover). It shows how climate change presents the greatest challenge-and the grandest opportunity-facing the human race. who "used to be the next President of the United States," as he breaks the emotional ice at the start of this fast paced film. With humour, humility, intelligence, and artistry, the film shows him traversing the globe. It paints a portrait of "Earth in the Balance" (the title of his 1992 book), perilously perched on a series of potential climatic tipping points.

Earth's polar ice caps have remained medium to large in size for more than 650000 years, switching in tandem with levels of atmospheric carbon dioxide $\left(\mathrm{CO}_{2}\right)$, ranging from 180 to 280 parts per million (ppm). At the current $\mathrm{CO}_{2}$ level of $380 \mathrm{ppm}$ we are outside that envelope and are sailing swiftly into uncharted, ice starved seas. Systems seek equilibriums. But we will be fortunate if the climate is able to re-stabilise

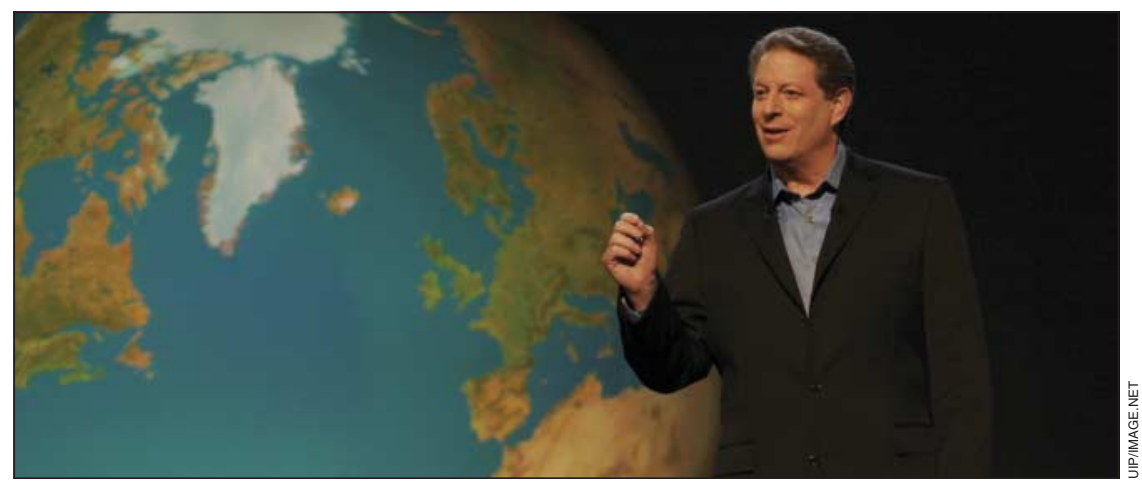

Al Gore challenges viewers to respond to climate change

at a state that affords a modicum of predictability and offers us a second chance to radically change our energy diet.

The underappreciated truth is that the oceans have warmed 22 times more than the atmosphere. Increased evaporation from warmer sea surfaces fuels intense storms; but the upwelling of warm water from the depths generates sequences of severe storms. The changes in storm intensity and shifting in the circulation of the Atlantic Ocean observed today match the magnitude that models predicted would occur in 2080 .

Using marvellous animations, the film portrays how sea water is warming, ice is melting, and water vapour is rising. It shows how the accelerating hydrological cycle is driving more droughts and more intense downpours. As temperatures and pressure gradients increase, it explains how this causes greater wind speeds and wider swings in weather.

The dwindling ice cover receives special attention in An Inconvenient Truth, with the stark warning that many montane glaciers will soon disappear. In Greenland, some outlet glaciers are heading towards the sea at a rate of $14 \mathrm{~km} /$ year-twice the rate they were slipping only five years ago-caused by melt water seeping down through crevasses to lubricate their bases. Linear projections for the rise in sea level this century no longer apply, and this film, skilfully crafted by the director, David Guggenheim, graphically demonstrates the potential implications for coastal zones from London to Manhattan, and Calcutta to Shanghai.

The changes depicted hold enormous implications for human health and wellbeing. Global warming, greater variability in weather patterns, and changes to the timing of seasons are destabilising ecological dynamics. They are disrupting the annual rhythms of pollinators, affecting plant
Hyperbole? Not according to Al Gore, patterns, and predators, which are central in preventing prey from becoming pests and carriers of pathogens. The health of humans, forests, crops, wildlife, and marine life are all at stake. Coral reefs, the oldest habitat on Earth and the "medicine chests of the sea," are under siege from warming induced bleaching and disease.

Behind probing the orbital harmonics of global climate change and the disharmonies generated by burning fossil fuels and felling forests, An Inconvenient Truth contains an underlying, chaconne-like pulse of profound personal experiences: Gore's son's near death accident, which transformed his perspective on mankind's common future, and his sister's early death from lung cancer due to smoking, which led Gore's stricken father to abandon tobacco farming. The analogy between the tobacco industry's intransigence and untruths, and those still emanating from a flagging few fossil fuel companies are not lost on Gore.

We see a young Gore at Harvard in 1968, studying with Roger Ravelle, the eminent explorer of Earth's biogeochemical cycles, seeking to unravel the significance of the seesawing, up-ticking Keeling Curve-the critical measurement of atmospheric $\mathrm{CO}_{2}$ begun on the remote mountain peak of Mauna Loa, Hawaii, in 1957, the first International Geophysical Year. Gore's concern with global warming is no passing fancy.

The film stops short of solutions. But Gore is a cofounder of Generation Investment Management, a force in promoting the necessary shift of investments into clean technologies. Quantum jumps in losses from catastrophic weather events in the past two decades have stunned the financial sector; and institutional investors are readying to come about, given the right public policy signals.

The convenient truth is that, provided there is the proper magnitude of incentives and alignment of regulations, the clean energy transition can become the engine of growth for the 21st century. And the $\mathrm{Al}$ Gore we come to know through this adeptly arranged film may be just the statesperson who can to help the United States rejoin the community of nations in embarking on this essential project.

Paul R Epstein associate director, Center for Health and the Global Environment, Harvard Medical School

paul_epstein@hms.harvard.edu

Items reviewed are rated on a 4 star scal $(4=$ excellent $)$ 


\section{Aill}

\section{Arctic art}

The Ship: The Art of Climate Change, an exhibition at the Natural History Museum, London SW7, until 3 September 2006 www.nhm.ac.uk/

\section{Rating: $\star \star \star$ is}

$\mathrm{P}$ at artists, scientists, and educators ogether on a ship, send them to the Arctic, and see how the artists translate their reactions to the rising sea

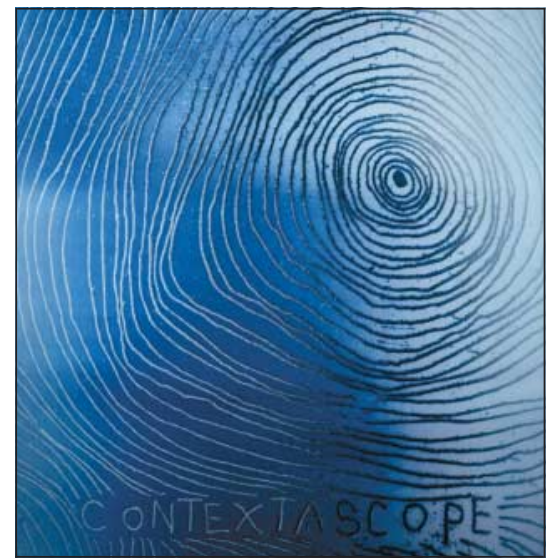

Contextascope by Michèle Noach levels, melting ice, and changes in biodiversity into art. This was the idea that prompted David Buckland, an artist, to set up the Cape Farewell organisation that took three expeditions to the Svalbard archipelago between 2003 and 2005 .

On these journeys, the artists drew, wrote, photographed, and filmed, and the exhibition at Natural History Museum in London brings together their works. The wide range of media and artists makes this exhibition a fascinating mix and certainly made me think. It also shows that art can be a powerful communicator of the science behind climate change.

From the sparkling skeleton of a whale (Stranded) and Gary Hume's comical painting (Hermaphrodite Polar Bear) to the bleak photographs by David Buckland and Gautier Deblonde, and the eerie soundtrack of cracking, melting ice-all manage to give an insight into the experiences of the artists. During one expedition, an artist discovered an island that had appeared as a glacier retreated. The discovery, claiming, naming, and registration of Nymark (Norwegian for new ground) are recorded in a series of framed documents and photographs.

Photographs show how artist Antony Gormley and architect Peter Clegg collaborated on Three Made Places, ice works made in the Arctic that show the spaces humans occupy individually and collectively. Choreographer Siobhan Davies also concentrates on humans-Endangered Species is a museum display case showing a film projection of a woman dancing in a costume of flexible rods that eventually extinguish her. Trying to combine science with emotion, Michèle

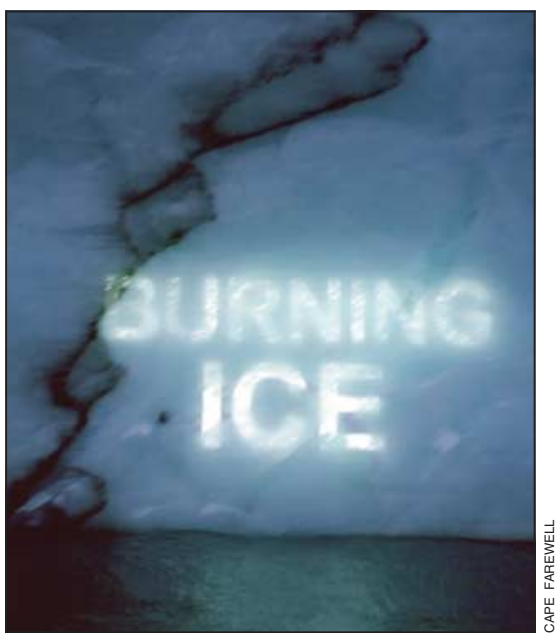

Ice Burning Ice by David Buckland

Noach made a series of images from hundreds of tiny lenses called The Arctic Feel-o-Graphs-fantasy scientific charts and graphs that structure her response to the Arctic environment.

If you're feeling inspired by the artworks to do your own bit towards helping the environment, then visit the interactive "ideas tank" where a touch-screen video helps you explore a collection of green ideas, including ecodesign courses, "gooshing" (an online guide to ethical shopping), and home brewed fuel; you can then email the links to yourself.

Sally Carter technical editor, BMJ

scarter@bmj.com

\section{How We Can Save the Planet}

Mayer Hillman, with Tina Fawcett
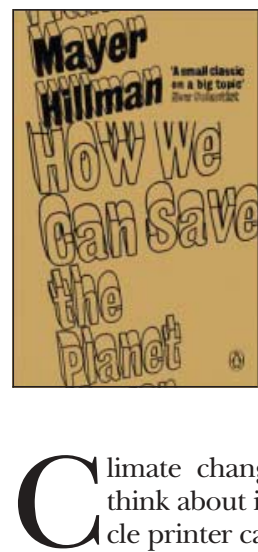

Penguin, £7.99, pp 195 ISBN 0141016922

Rating: $\star \star \star \star$ and use public transport when we can. We think that hydrogen vehicles are the transport of the future and that, thanks to big research grants from benign energy companies, the best brains in Britain are working on how to keep climate change at bay. In other words, we have lost the plot.

I read How We Can Save the Planet on a beach in Crete. It slapped me across the face with the reality of climate change. I felt embarrassed that I knew so little about the most important crisis facing humanity and was ashamed at the realisation that my personal carbon profligacy was part of the problem.

The author, Mayer Hillman, of the Policy Studies Institute, London, has a track record of speaking uncomfortable truths even before they become uncomfortable. In the late eighties, while the Department of Transport was congratulating itself on reducing pedestrian deaths, Hillman pointed out that death rates were falling because the roads were getting more dangerous-not less. He was right. Road danger was driving a massive decline in walking-so there were fewer pedestrians to be killed-and today's epidemic of fat kids is one of the direct consequences of this.

Like most people, I like to feel good about myself, but when the budget airliner taking me home from Crete thrust its engines and belched its way skyward, I felt like a pathetic environmental hypocrite. I was taking something that did not belong to me and trashing it. Blissfully ignorant on the way out to Crete, on the way home I was burdened by the guilty secret that I had personally soiled the upper atmosphere with nearly two tonnes of carbon dioxide. It will steam there for more than a century, contributing to the deaths by hunger, infection and war, of millions of people living in wretched poverty and whose collective carbon footprint is lighter than that of a sparrow walking on sand.

Don't read this book if you want to feel good about yourself. Kid yourself that the evidence for climate change is not that strong, that technology will come to the rescue and that the government can be relied on to sort it out. Just don't tell your kids because they will never forgive you. Once you have read Hillman's book, you will be saddled with a personal responsibility for the rest of your life. You will understand why greater use of public transport and hydrogen power are not the answers. You will know why personal carbon rationing is the only viable solution, that it must happen now and that it will impact on every aspect of your life. Read this book and there is no going back.

Ian Roberts professor of epidemiology and population health, London School of Hygiene and Tropical Medicine

Ian.Roberts@Ishtm.ac.uk 
PERSONAL VIEW

\section{A magical education}

$\mathrm{O}$

ne afternoon a week, when tired of thinking about medical ethics, I put on my volunteer's badge, pick up my cards and coins, and head over to the nearby hospital. In large, black letters, the badge reads "MAGICIAN."

For a few hours, I meander through the wards, performing tricks for the "guests" and their relatives. At the bedside, a large silk scarf vanishes and reappears before their eyes, three coins jump invisibly from one hand to the next, a $£ 5$ note changes into $£ 20$, two cards change places in a blink of an eye, a signed card disappears from the deck, only to reappear in my wallet, and so on.

In my first week as a hospital magician, I nearly vomited twice. In one oncology ward, the stench of urine and faeces was such that I could barely finish my first trick. I held my breath, rushed to the end, and briskly walked out, gasping for air. Looking back, I should have told the nurse about the situation. No human being should endure such odours.

The second time was in the rheumatology ward, when I performed for a young man whose badly broken leg was perforated by metal rods at several places. Standing at the end of the bed, I could see that the area surrounding each entry point looked like the inside of a red and rotting fruit. I gagged at the sight, but somehow kept my composure.

When patients are doubly incontinent, when their bones are shattered, when their flesh is riddled with cancer or their heads covered in a constellation of sutures following neurosurgery, I wonder why some should care about magic. The main weapon of the close-up magician is not sleight of hand, as is commonly believed, but misdirection: diverting the spectator's attention away from secret operations. As a hospital magician, misdirection adopts another meaning. For a handful of minutes, it diverts patients' attention away from their experience of illness, their impending tests or surgery, the tubes and the drips, and the gloomy surroundings. In return, they divert mine away from the trivialities and pettifoggery of academic life. When I perform, publications in high impact factor journals are the last thing on my mind. And when I open my wallet to reveal a card, and sense a momentary astonishment, I no longer care that the wallet is otherwise thin.

My role as a hospital magician has opened my eyes to many aspects of health care and ethics (both medical and personal). I shall mention only two.
The first relates to hospital life in general. There is, in British hospitals, an epidemic of boredom. Unless in agony or in the throes of death, hospitals are terribly dull places for patients. The dreary silence of the wards often screams out for excitement and activity. The books, magazines, and crosswords will not do, and neither will the toing and froing of various staff members. Although the dreariness is undoubtedly effective in encouraging patients to go home, the mood on the wards sometimes borders on the suicidal. I often wonder whether better entertainment would result in fewer patient complaints. And if immunological states are indeed linked to mental states (as suggested by the "placebo effect"), lifting patients' spirits may even improve their recovery. "Send in the clowns," as the song goes, and splash the walls with coloured paint. As with military service in France, all amateur and professional magicians (and other suitable entertainers) should devote one day a year to visiting a hospital ward. They would learn much from the experience.

The second deals with what I consider an important lacuna in the education of many academic medical ethicists. For most ethicists, hospitals are mysterious places. Large and impersonal, festering with invisible bugs and transient bodies, echoing with inhospitable sounds of pain, relief, anger, and other primeval human emotions, the hospital is viewed as a melting pot of moral issues to be addressed-from a distance This unfamiliarity is cause for regret, as it perpetuates the chasm between theory and practice and contributes to the tension between ethicists and healthcare professionals. The latter often complain that ethicists are too theoretical and out of touch, while the former grumble at the lack of philosophical rigour in doctors' reasoning. At present, in the United Kingdom, only illness or injury will allow an ethicist to experience a hospital ward. Brief hospital internships to expose them to the realities of clinical practice would do much to remedy these problems. Welcoming ethicists into the nitty gritty of medicine would result in more empirically informed advice and greater collaboration between academics and practitioners on real life issues.

Daniel K Sokol PhD candidate, medical ethics unit, department of primary health care and general practice, Imperial College London, and hospital magician, Charing Cross Hospital daniel.sokol@talk21.com

\section{SOUNDINGS}

\section{The threat}

In Aliens, the human colonists have been eradicated by the ruthless queen. As Sigourney Weaver is escaping, she loses the little girl she has promised never to leave. She returns to the hive and, as she straps on her guns, the camera lingers. Her face is grim, and you realise that she is more dangerous than any monster. Hunters have a saying: "Never get between a she-bear and her cubs."

We general practitioners also have a saying: "Never get between an elderly woman and her tablets." Not quite the same: elderly women don't actually love their tablets; "Love is not love, Which alters when it alteration finds," but the effect is similar.

I remember, as a junior doctor, admitting an elderly woman who was on about 40 different medications, and we were scathing about indolent GPs prescribing willy-nilly. With youthful innocence we stopped all her medications, and to our satisfaction she began to perk up. Unfortunately, as she perked up, she also realised that she was drug free, and over the next few weeks she remorselessly wore us down, day by day, tablet by tablet; firstly (of course), the hypnotic, then an anxiolytic, then an antidepressant, her vitamins, her aspirin, her antihypertensive, etc etc. By discharge we had capitulated and thrown in a few more, just for show.

Nothing changes; polypharmacy thrives. Why? I write prescriptions, so why can't I just say no? I won't be offended if patients change doctors, and the financial loss will be minimal.

I was trying to rationalise Maggie's particular cocktail, unchanged for millenniums. "You won't need these," I said, reaching for the levodopa on her overloaded shelf.

My wrist was caught in a vice-like grip. Terry Pratchett observed that whole economies have been built on the ability of elderly women to carry massive loads on their backs; they look frail, but they're wiry.

"Dr Sloan said these would help," she said. Dr Sloan, I guessed, was some harassed junior doctor from the mists of time, trying to escape his coffee break by pretending he was actually doing something, but no edict from Pope Pius could have carried greater weight or echoed so grandly down the years.

"He was a very good doctor," I agreed, as she was between me and the door. A prescription has many fathers, and physical intimidation is yet another.

Liam Farrell general practitioner, Crossmaglen, County Armagh 